\title{
Traditional medicine practices among community members with diabetes mellitus in Northern Tanzania: an ethnomedical survey
}

Joseph Lunyera ${ }^{1 *}$ (D, Daphne Wang ${ }^{1}$, Venance Maro², Francis Karia², David Boyd ${ }^{1}$, Justin Omolo ${ }^{3}$, Uptal D. Patel ${ }^{1,4}$, John W. Stanifer ${ }^{1,5,6}$ and for the Comprehensive Kidney Disease Assessment For Risk factors, epidemiology, Knowledge, and Attitudes (CKD AFRiKA) Study

\begin{abstract}
Background: Diabetes is a growing burden in sub-Saharan Africa where traditional medicines (TMs) remain a primary form of healthcare in many settings. In Tanzania, TMs are frequently used to treat non-communicable diseases, yet little is known about TM practices for non-communicable diseases like diabetes.

Methods: Between December 2013 and June 2014, we assessed TM practices, including types, frequencies, reasons, and modes, among randomly selected community members. To further characterize TMs relevant for the local treatment of diabetes, we also conducted focus groups and semi-structured interviews with key informants.

Results: We enrolled 481 adults of whom 45 (9.4\%) had diabetes. The prevalence of TM use among individuals with diabetes was $77.1 \%$ (95\% Cl 58.5-89.0 \%), and the prevalence of using TMs and biomedicines concurrently was $37.6 \%$ (95 \% Cl 20.5-58.4\%). Many were using TMs specifically to treat diabetes (40.3\%; $95 \% \mathrm{Cl} 20.5-63.9)$, and individuals with diabetes reported seeking healthcare from traditional healers, elders, family, friends, and herbal vendors. We identified several plant-based TMs used toward diabetes care: Moringa oleifera, Cymbopogon citrullus, Hagenia abyssinica, Aloe vera, Clausena anisata, Cajanus cajan, Artimisia afra, and Persea americana.

Conclusions: TMs were commonly used for diabetes care in northern Tanzania. Individuals with diabetes sought healthcare advice from many sources, and several individuals used TMs and biomedicines together. The TMs commonly used by individuals with diabetes in northern Tanzania have a wide range of effects, and understanding them will more effectively shape biomedical practitices and public health policies that are patient-centered and sensitive to TM preferences.
\end{abstract}

Keywords: Biomedicine, Traditional medicine, Sub-Saharan Africa, Low- and middle-income countries, Noncommunicable diseases

\footnotetext{
* Correspondence: josephlunyera@gmail.com

'Duke Global Health Institute, Duke University, 310 Trent Drive, Durham, NC

27705, USA

Full list of author information is available at the end of the article
} 


\section{Background}

The prevalence of diabetes mellitus (DM) is rapidly growing globally with a disproportionate burden falling on low- and middle-income regions [1]. In sub-Saharan Africa, DM prevalence is now as high as $18 \%$ in some countries and current estimates portend that the prevalence of DM in the region could nearly double by the year 2045, which means that more than 40 million people would be living with diabetes in sub-Saharan Africa [2]. Despite this, access to biomedical healthcare remains limited for most populations in the region $[3,4]$. Health systems and healthcare clinics are currently under-prepared to adequately meet the demands of caring for non-communicable diseases (NCDs) such as DM $[5,6]$. In this setting, traditional medicines (TMs), which are defined by the World Health Organization (WHO) as "the sum total of the knowledge, skills, and practices based on the theories, beliefs, and experiences indigenous to different cultures, whether explicable or not, used in the maintenance of health as well as in the prevention, diagnosis, improvement or treatment of physical and mental illness [7]," are critical in meeting the healthcare needs for much of the population [8]. The WHO World Health Assembly and regional committees, including the WHO African regional committee and African heads of states, have adopted resolutions which formally recognized TMs as pivotal in health service delivery. They also urged governments to integrate TMs into their health system based on innovation and research [7, 9-11]. However, in the context of NCDs, for the most part these resolutions remain unmet due to limited understanding of population-based TM practices [12, 13].

In Tanzania, TM use is frequent with more than half of all adults regularly using TM [14]. They are used for treating a variety of conditions, including NCDs $[12,15]$. However, little is known about the types, modes, frequencies, reasons for use, and pharmacology of TMs used to manage NCDs especially as they pertain to DM [12-16]. Considering the burden of DM, characterizing TM practices among community members with and at risk for DM will be important in formulating optimal disease management programs and public health efforts in the region [13].

As part of the Comprehensive Kidney Disease Assessment for Risk Factors, epidemiology, Knowledge, and Attitudes (CKD AFRiKA) study in Northern Tanzania, we conducted assessments among community-based adults using focus-group discussions, in-depth interviews, and structured surveys. We sought to characterize the use of TMs among a community-based population in order to help shape public health efforts and biomedical practices addressing DM in ways that are sensitive to local TM practices. Specifically, we described TM practices among community members with DM including the types, frequencies, modes, and pharmacological descriptions of those relevant to DM care.

\section{Methods \\ Study setting}

The CKD AFRiKA Study was conducted in December 2013-June 2014 and March-June 2015 in the Kilimanjaro Region of Tanzania. The region has an adult population of 900,000 for which KCMC hospital serves as the tertiary referral hospital. Patients pay a standard fee scaled to their income for their clinical care at the hospital and the hospital-based clinics [17]. The majority of the population lives in rural settings (65\%). The unemployment rate is $19 \%$, and the majority of adults have a primary education or less (77\%). The largest ethnic group is the Chagga tribe followed by the Pare, Sambaa, and Maasai tribes. Swahili is the major language, and all participants in our study spoke it as their first language [18].

\section{Quantitative data collection}

We developed a structured survey instrument designed to test different factors related to TM practices among community members (Additional file 1). The development of the survey instrument has been previously described [14, 19]. In brief, the instrument was drafted in English by local and non-local experts from the fields of medicine, epidemiology, sociology, anthropology, and public health. It was independently translated into Swahili by two native speakers with joint review of each version. We piloted it through several qualitative sessions in an iterative process in order to ensure the content validity of the survey instrument. The final version of the survey instrument included nine items including both open-ended questions related to types of TMs used by community members as well as close-ended questions related to frequency of use, reasons for use, modes of use, modes of access, and conditions treated by TMs.

Using two local surveyors, we verbally administered the survey to adult community members from the Moshi Urban and Moshi Rural districts of the Kilimanjaro Region. The overall sample size was based on the requirements of the CKD AFRiKA study, which was designed to estimate the community prevalence of chronic kidney disease with a precision of $5 \%$ when accounting for the cluster-design effect. Using a random-number generator, we selected thirty seven sampling areas from twenty-nine neighborhoods, stratified by urban and rural. We based the random neighborhood selection on probability proportional to size using the 2012 Tanzanian National Census [18]. Within each neighborhood the sampling area was determined using geographic points randomly generated using Arc Global Information Systems (ArcGIS), 
v10.2.2 (Environmental Systems Research Institute, Redlands, CA), and households were then randomly chosen based on coin-flip and die-rolling techniques [20]. All adults living in the selected households were recruited, and all Tanzanian citizens over the age of 18 were eligible for inclusion. To reduce non-response rates, we attempted a minimum of two additional visits on subsequent days and weekends, and using mobile phone numbers, we located eligible participants through multiple phone calls.

\section{Qualitative data collection}

As part of the CKD AFRiKA Study, we conducted focus group discussions (FGDs) and in-depth interviews in a central, easily accessible location. These sessions have been described previously, but in brief, we conducted five FGDs and 27 in-depth interviews both of which included key informants from the community including well-adults from the general population, chronically-ill adults receiving care at the hospital medicine clinics, adults receiving care from traditional healers, adults purchasing TMs from herbal vendors, traditional healers, herbal vendors, and medical doctors [14].

\section{Disease definitions}

Participants were assessed for DM as part of the CKD AFRiKA Study [20]. Hemoglobin (Hb) A1c was measured from a fingerstick whole blood sample using the Bayer A1c Now+ point-of-care device (Bayer Healthcare LLC; Sunnyvale, CA). DM was considered present if the HbA1c level was greater than $7.0 \%(53 \mathrm{mmol} / \mathrm{mol})$ or current known use of anti-hyperglycemic medications for the purpose of treating diabetes. We considered participants to be at increased risk for diabetes if their HbA1c was between $6.0 \%(42 \mathrm{mmol} / \mathrm{mol})$ and $6.9 \%$ (52 $\mathrm{mmol} / \mathrm{mol}$ ) in the absence of ongoing treatment with anti-hyperglycemic medicines.

\section{Data analysis and management}

Quantitative data were analyzed using STATA v.13 (STATA Corp., College Station, TX). The median and inter-quartile ranges (IQR) were reported for continuous variables. All $p$ values are two-sided at a 0.05 significance level. To compare differences between groups, we used a Chi squared test or Fisher's Exact test. Prevalence estimates were sample-balanced using age- and genderweights based on the 2012 urban and rural district-level census data, and they are reported with $95 \%$ confidence intervals (CI) [21]. We used Taylor Series linearization to account for the design effect due to cluster sampling. All data were collected on paper and then electronically entered into and managed using REDCap electronic data capture tools hosted at Duke University. REDCap is a secure, web-based application designed to support data capture for research studies [21]. All data were verified after electronic data entry by an independent reviewer to ensure accuracy.

To identify traditional medicines used for the treatment of DM, two authors (JL and DW) independently reviewed the transcripts of the FGDs and in-depth interviews conducted as part of the CKD AFRiKA Study. All TMs referenced by participants were recorded in the coding index, and analytic memos were created for TMs referenced for treatment of DM. A third author (JO) familiar with local languages, dialects, and customs, then cross-referenced the local vernacular with known botanical and linguistic catalogues in the region and country. Any discrepancies were resolved by joint consensus. All of the qualitative data, including the coding index, were recorded and managed using NViVO v.10.0 (QRS International Pty Ltd, Melbourne, Australia).

\section{Results}

Demographics of study participants

We enrolled 481 participants in the CKD AFRiKA Study. Forty-five participants (9.4\%) had DM, and 84 (17.5\%) were at increased risk for DM. The household non-response rate was $15.0 \%$, and the individual nonresponse rate was $21.0 \%$. Compared to the regional census data, men $(p<0.001)$ and young adults $(18-39$ years old; $p=0.001$ ) were more likely to be non-responders [18]. The most common reason for non-response was inability to locate or contact individuals.

Adults with DM were mostly female $(n=30$; $66.7 \%), \geq 40$ years of age $(n=40 ; 88.9 \%)$, urban residents $(n=39 ; 86.7 \%)$, ethnically Chagga $(n=26$; $57.8 \%)$, Protestant $(n=22 ; 48.9 \%)$, and had a primary school education $(n=26 ; 57.8 \%)$ (Table 1$)$. The median age of adults with DM was 59 (IQR 48-68) years old. Several participants with DM were unaware of having it $(n=16 ; 35.6 \%)$, but many did report a history of hypertension $(n=21 ; 46.7 \%)$. Few reported a history of heart disease, kidney disease, stroke, chronic obstructive pulmonary disease (COPD), or human immunodeficiency virus (HIV). Alcohol use was common $(n=28 ; 62.2 \%)$ but few reported a history of smoking ( $n=13 ; 28.9 \%)$.

Among those at increased risk for DM $(n=84)$, most were female $(n=65 ; 77.4 \%)$, ethnically Chagga ( $n=45 ; 54 \%)$, urban residents $(n=63 ; 75.0 \%)$, and had a primary school education $(n=63 ; 75.0 \%)$. Unlike those with diabetes, they were younger (median age $=42$ years; IQR $33-56)(p<0.01)$ and were more likely to be occupied as farmers or wage earners $(n=32 ; 38.1 \%)(p<0.01)$.

\section{Epidemiology of traditional medicine use}

The prevalence of adults with DM reporting any TM use was $77.1 \%$ (95 \% CI 58.5-89.0 \%) (Table 2). 
Table 1 Participant characteristics by diabetes and diabetes risk status; CKD-AFRIKA study population, 2014; N=481

\begin{tabular}{|c|c|c|c|c|c|}
\hline \multirow[t]{3}{*}{ Variable } & \multicolumn{4}{|l|}{ Participants } & \multirow{3}{*}{$p$-value ${ }^{*}$} \\
\hline & \multirow[t]{2}{*}{ Overall $(n=481)$} & \multicolumn{2}{|c|}{ Diabetes Absent $(n=436)$} & \multirow[t]{2}{*}{ Diabetes Present $(n=45)$} & \\
\hline & & $\begin{array}{l}\text { Low risk } \\
(n=352)\end{array}$ & $\begin{array}{l}\text { Increased risk } \\
(n=84)\end{array}$ & & \\
\hline \multicolumn{5}{|l|}{ Gender } & 0.21 \\
\hline Male & $123(26 \%)$ & $89(25 \%)$ & 19 (23\%) & $15(33 \%)$ & \\
\hline Female & $358(74 \%)$ & $263(75 \%)$ & $65(77 \%)$ & $30(67 \%)$ & \\
\hline \multicolumn{5}{|l|}{ Age } & $<0.01$ \\
\hline 18-39 years old & $172(36 \%)$ & $143(41 \%)$ & $24(29 \%)$ & $5(11 \%)$ & \\
\hline 40-59 years old & 191 (40 \%) & 135 (38 \%) & 37 (44 \%) & 19 (42\%) & \\
\hline $60+$ years old & $118(24 \%)$ & $74(21 \%)$ & $23(27 \%)$ & $21(47 \%)$ & \\
\hline \multicolumn{5}{|l|}{ Setting } & 0.10 \\
\hline Rural & $111(23 \%)$ & $84(24 \%)$ & $21(25 \%)$ & $6(13 \%)$ & \\
\hline Urban & $370(77 \%)$ & $268(76 \%)$ & $63(75 \%)$ & 39 (87 \%) & \\
\hline \multicolumn{5}{|l|}{ Ethnicity } & 0.50 \\
\hline Chagga & $288(60 \%)$ & 217 (62 \%) & $45(54 \%)$ & $26(58 \%)$ & \\
\hline Pare & $66(14 \%)$ & $43(12 \%)$ & $19(23 \%)$ & $4(9 \%)$ & \\
\hline Sambaa & $27(6 \%)$ & $22(6 \%)$ & $3(4 \%)$ & $2(4 \%)$ & \\
\hline Other ${ }^{a}$ & $100(20 \%)$ & $70(20 \%)$ & 17 (20\%) & $13(29 \%)$ & \\
\hline \multicolumn{5}{|l|}{ Religion } & 0.18 \\
\hline Roman Catholic & $192(40 \%)$ & 149 (42 \%) & $31(37 \%)$ & $12(27 \%)$ & \\
\hline Protestant & $161(33 \%)$ & $117(33 \%)$ & $22(26 \%)$ & $22(49 \%)$ & \\
\hline Islam & $123(26 \%)$ & $84(24 \%)$ & $28(33 \%)$ & $11(24 \%)$ & \\
\hline Hindu & $2(<1 \%)$ & $1(<1 \%)$ & $1(1 \%)$ & $0(0 \%)$ & \\
\hline \multicolumn{5}{|l|}{ Education } & 0.06 \\
\hline None & $31(6 \%)$ & $21(6 \%)$ & $4(5 \%)$ & $6(13 \%)$ & \\
\hline Primary & $349(73 \%)$ & $260(74 \%)$ & $63(75 \%)$ & $26(58 \%)$ & \\
\hline Secondary & $74(15 \%)$ & $52(15 \%)$ & $12(14 \%)$ & $10(22 \%)$ & \\
\hline Post-Secondary & $27(6 \%)$ & $19(5 \%)$ & $5(6 \%)$ & $3(7 \%)$ & \\
\hline \multicolumn{5}{|l|}{ Occupation } & $<0.01$ \\
\hline Unemployed & $74(15 \%)$ & $52(15 \%)$ & $15(18 \%)$ & $7(16 \%)$ & \\
\hline Farmer/Wage Earner & 199 (41%) & $157(45 \%)$ & $32(38 \%)$ & $10(22 \%)$ & \\
\hline Small Business/Vendors & $158(33 \%)$ & $121(34 \%)$ & $25(30 \%)$ & $12(27 \%)$ & \\
\hline Professional $^{b}$ & $50(10 \%)$ & $22(6 \%)$ & $12(14 \%)$ & $16(36 \%)$ & \\
\hline History of Smoking & $117(24 \%)$ & $85(24 \%)$ & $19(23 \%)$ & $13(29 \%)$ & 0.45 \\
\hline History of alcohol intake & $318(66 \%)$ & $236(67 \%)$ & $54(64 \%)$ & $28(62 \%)$ & 0.56 \\
\hline \multicolumn{6}{|l|}{ Self-Reported Medical History } \\
\hline Hypertension & $134(28 \%)$ & 86 (25 \%) & 27 (32 \%) & $21(47 \%)$ & $<0.01$ \\
\hline Diabetes & $61(13 \%)$ & $23(7 \%)$ & $9(11 \%)$ & 29 (64 \%) & $<0.01$ \\
\hline Heart Disease $^{c}$ & 18 (4 \%) & 10 (3 \%) & $3(4 \%)$ & $5(11 \%)$ & 0.01 \\
\hline HIV & $21(4 \%)$ & $21(6 \%)$ & $0(0 \%)$ & $0(0 \%)$ & 0.24 \\
\hline Stroke & $8(2 \%)$ & $6(2 \%)$ & $0(0 \%)$ & $2(4 \%)$ & 0.17 \\
\hline COPD & $8(2 \%)$ & $6(2 \%)$ & $1(1 \%)$ & $1(2 \%)$ & 0.55 \\
\hline Kidney Disease & 14 (3%) & 7 (2 \%) & $3(4 \%)$ & 4 (9 \%) & 0.03 \\
\hline
\end{tabular}

COPD Chronic obstructive pulmonary disease

*P-value comparing differences by diabetes status (present or absent)

a Other ethnicities includes Maasai, Luguru, Kilindi, Kurya, Mziguwa, Mnyisanzu, Rangi, Jita, Nyambo, and Kaguru

${ }^{\mathrm{b}}$ Professional included any salaried position (e.g. nurse, teacher, government employee, etc.) and retired persons

${ }^{c}$ Heart disease included coronary disease, heart failure, or structural diseases 
Table 2 Epidemiology and characteristics of traditional medicine use stratified by diabetes and diabetes risk status; CKD-AFRIKA

\begin{tabular}{|c|c|c|c|}
\hline & \multicolumn{2}{|c|}{ Diabetes Absent; $n=436(95 \%$ Cl) } & \multirow{2}{*}{$\begin{array}{l}\text { With Diabetes; } \\
n=45(\%, 95 \% \text { Cl) }\end{array}$} \\
\hline & Low risk $(n=352)$ & Increased risk $(n=84)$ & \\
\hline \multicolumn{4}{|l|}{ Prevalence } \\
\hline ... of TM Use & $60.3 \%(48.9-70.7)$ & $56.7 \%(43.4-69.2)$ & $77.1 \%(58.5-89.0)$ \\
\hline ... of concurrent TM and Biomedicine Use & $4.9 \%(2.7-8.9)$ & $2.6 \%(0.8-7.6)$ & $37.6 \%(20.5-58.4)$ \\
\hline \multicolumn{4}{|l|}{ Incidence of TM Use (per year) } \\
\hline $1-5$ times & $47.2 \%(38.8-55.7)$ & $32.0 \%(19.9-47.1)$ & $45.3 \%(27.8-64.0)$ \\
\hline $6-10$ times & $7.7 \%(4.6-12.6)$ & $17.0 \%(7.8-33.0)$ & $5.2 \%(1.5-16.1)$ \\
\hline$>10$ times & $5.4 \%(3.1-9.4)$ & $7.1 \%(2.6-18.0)$ & $26.7 \%(10.2-53.8)$ \\
\hline \multicolumn{4}{|l|}{ Reasons for TM Use } \\
\hline More Effective & $83.3 \%(74.6-89.4)$ & $81.4 \%(62.8-91.9)$ & $79.6 \%(40.4-95.7)$ \\
\hline Lower Cost & $60.1 \%(48.2-70.9)$ & $64.5 \%(46.4-79.3)$ & $55.2 \%(32.2-76.2)$ \\
\hline Easier to Access & $69.9 \%(61.0-77.6)$ & $61.6 \%(45.0-75.8)$ & $59.1 \%(30.7-82.5)$ \\
\hline Safer & $43.4 \%(31.6-56.1)$ & $39.1 \%(25.8-54.2)$ & $39.5 \%(20.4-62.5)$ \\
\hline More Traditional/Religious & $30.4 \%(23.4-38.4)$ & $29.7 \%(18.0-44.8)$ & $42.0 \%(24.1-62.3)$ \\
\hline \multicolumn{4}{|l|}{ Modes of Healthcare Access } \\
\hline Medical Doctors & $97.3 \%(93.4-98.9)$ & $97.2 \%(85.3-99.5)$ & $90.5 \%(58.6-98.5)$ \\
\hline Family and Elders & $50.7 \%(38.0-63.4)$ & $55.4 \%(34.4-74.6)$ & $69.0 \%(42.8-86.9)$ \\
\hline Traditional Healers & $5.6 \%(2.7-11.0)$ & $9.9 \%(3.0-28.2)$ & $22.9 \%(8.2-49.7)$ \\
\hline Pharmacists & $19.9 \%(11.9-31.3)$ & $22.0 \%(10.5-40.5)$ & $10.6 \%(3.9-25.5)$ \\
\hline Herbal Vendors & $3.9 \%(1.1-12.2)$ & $11.4 \%(5.7-21.5)$ & $5.1 \%(1.5-16.1)$ \\
\hline Friends/Neighbors & $17.5 \%(10.4-27.8)$ & $16.7 \%(9.7-27.4)$ & $5.2 \%(1.7-15.3)$ \\
\hline \multicolumn{4}{|l|}{ TM Use } \\
\hline ...for Symptomatic Ailments & $57.3 \%(49.2-65.0)$ & $45.1 \%(28.8-62.6)$ & $79.1 \%(60.8-90.2)$ \\
\hline ...for Chronic Diseases & $27.7 \%(19.1-38.0)$ & $24.5 \%(12.9-41.5)$ & $57.0 \%(29.4-80.9)$ \\
\hline ...for Reproductive/Fertility Ailments & $22.8 \%(14.6-33.9)$ & $19.7 \%(8.8-38.5)$ & $49.5 \%(28.2-70.9)$ \\
\hline ...for Malaria/Febrile IIInesses & $56.7 \%(43.1-69.4)$ & $70.9 \%(58.2-80.9)$ & $59.2 \%(28.7-84.0)$ \\
\hline ...for Spiritual/traditional uses & $8.6 \%(4.5-15.7)$ & $7.0 \%(2.2-20.2)$ & $9.4 \%(3.5-22.8)$ \\
\hline ...for Neurologic Illnesses & $19.5 \%(11.3-31.4)$ & $19.6 \%(10.2-34.5)$ & $38.2 \%(18.9-62.2)$ \\
\hline ...for Urogenital Conditions & $15.7 \%(9.8-24.4)$ & $16.7 \%(8.2-31.0)$ & $26.0 \%(10.6-51.1)$ \\
\hline ...for Cancers & $14.7 \%(6.6-29.7)$ & $9.0 \%(3.0-23.8)$ & $22.9 \%(8.0-50.6)$ \\
\hline ...for Disease Prevention & $5.9 \%(3.3-10.3)$ & $0.7 \%(0.1-5.8)$ & $11.4 \%(3.0-34.9)$ \\
\hline ...for Worms/Parasites & $11.1 \%(6.9-17.4)$ & $15.9 \%(9.3-25.9)$ & $22.0 \%(8.7-45.7)$ \\
\hline \multicolumn{4}{|l|}{ Modes of TM Use } \\
\hline Mix with water & $83.0 \%(77.4-87.4)$ & $85.7 \%$ (75.2-92.3) & $79.8 \%$ (54.6-92.9) \\
\hline Drink as a tea & $61.1 \%(52.7-68.9)$ & $47.5 \%(31.0-64.5)$ & $62.7 \%(35.0-83.9)$ \\
\hline Drink as a soup & $46.1 \%(36.6-55.8)$ & $35.2 \%(25.5-46.4)$ & $65.5 \%(38.3-85.3)$ \\
\hline Chew from the plant & $57.5 \%(46.4-67.9)$ & $47.3 \%(31.9-63.3)$ & $58.3 \%(41.6-73.3)$ \\
\hline Drink with milk & $22.8 \%(15.7-31.9)$ & $15.7 \%(7.5-30.0)$ & $39.2 \%(19.2-63.6)$ \\
\hline Bath & $26.2 \%(17.7-37.0)$ & $30.3 \%(20.7-42.0)$ & $45.0 \%(19.3-73.8)$ \\
\hline Inhalation & $33.9 \%(26.5-42.1)$ & $39.2 \%(26.8-53.1)$ & $42.5 \%(24.0-63.3)$ \\
\hline Powders & $17.4 \%(9.7-29.2)$ & $22.9 \%(11.8-39.7)$ & $25.3 \%(9.9-51.0)$ \\
\hline As foods to be eaten & $2.4 \%(0.8-6.8)$ & $7.7 \%(2.0-25.5)$ & $4.2 \%(1.1-14.9)$ \\
\hline
\end{tabular}


Table 2 Epidemiology and characteristics of traditional medicine use stratified by diabetes and diabetes risk status; CKD-AFRIKA (Continued)

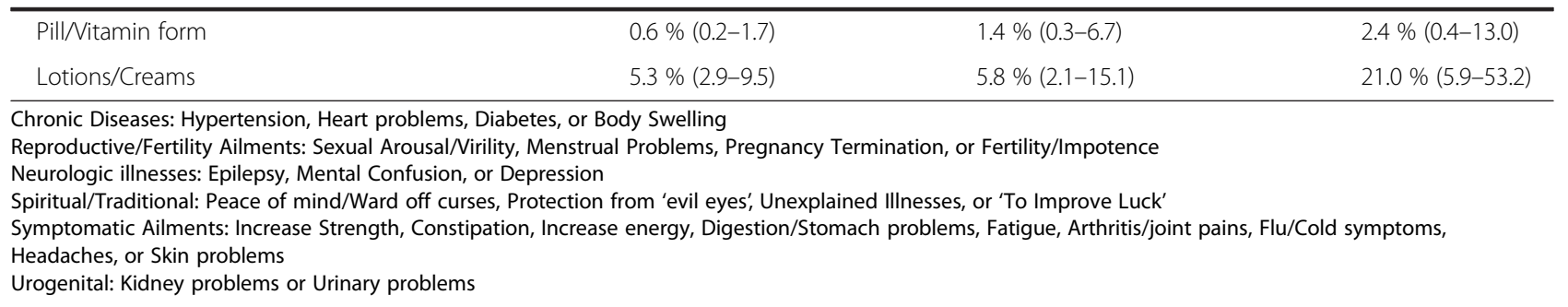

Most reported using TM 1-5 times per year (45.3\%; $95 \%$ CI 27.8-64.0\%), but many also reported use of more than 10 times per year (26.7\%; $95 \%$ CI $10.2-$ $53.8 \%)$. Fewer than half of adults with DM reported ongoing use of any biomedicine (42.2\%; $95 \%$ CI 24.3-62.4\%), and among these, nearly three-quarters ( $n=13 ; 72.2 \%)$ were also using TMs. As such, among all participants with DM, the prevalence of concurrent use of TM and biomedicine was $37.6 \%$ (95\% CI 20.5-58.4\%), which did not vary significantly by age, gender, occupation, or education (all $p$-values $>0.05$ ).

Adults with DM reported many reasons for the use of TMs (Table 2). When compared to biomedicines, the prevalence of TMs being reported as more effective was $79.6 \%$ (95\% CI 40.4-95.7\%), as easier to access $59.1 \%$ (95\% CI 30.7-82.5\%), as having lower costs $55.2 \%$ (95\% CI 32.2-76.2\%), as being more traditional/religious $42.0 \%$ (95 \% CI 24.1-62.3\%), and as being safer was $39.5 \%$ (95 \% CI 20.4-62.5\%).

Community members with DM accessed healthcare from several sources (Table 2). Although most of them reported accessing healthcare from medical doctors (90.5\%; $95 \%$ CI 58.6-98.5 \%), many also reported accessing healthcare from family and elders, traditional healers, and pharmacists. Some also reported seeking healthcare from herbal vendors (5.1\%; $95 \%$ CI 1.5-16.1\%) and friends/neighbors (5.2\%; $95 \%$ CI 1.7-15.3 \%). Individuals with DM reported using TMs most commonly for symptomatic ailments, malaria/febrile illness, chronic diseases, neurologic conditions, and reproductive/fertility ailments. The most common modes reported were mixing with water, tea, soup, or milk. Less frequently, they were reported as being inhaled, chewed, used with baths, lotions/creams, powders, or pill forms.

Many individuals were using TMs specifically for the treatment of their DM. The prevalence of TMs as a treatment choice for DM specifically was $40.3 \%$ (95\% CI 20.5-63.9). The prevalence of TMs alone as the treatment choice for DM was $29.1 \%$ (95 \% CI 13.4-52.0) which was comparable to the prevalence of biomedicine alone $(27.8 \%$; $95 \%$ CI 13.0-49.8) as the treatment choice for DM (Fig. 1). Most commonly, individuals with DM were receiving no treatment (31.9\%; $95 \%$ CI 14.4-56.5\%), either in the form of TM or biomedicine.

The prevalence of TM use was also high (56.7\%; $95 \%$ CI 43.4-69.2 \%) among adults at increased risk for DM (Table 2). Most reported using TMs 1-5 times per year $(32.0 \%$; $95 \%$ CI $19.8-47.2 \%)$ or $6-10$ times per year (17.0\%; $95 \%$ CI 7.8-33.0\%). However, unlike adults with DM, those at risk for DM had a lower prevalence of biomedicine use (4.3\%; $95 \%$ CI 1.7-10.4\%).

\section{Traditional medicines used for the treatment of diabetes in Northern Tanzania}

We identified 168 plant-based TMs referenced by participants as part of the qualitative sessions and open-ended structured survey items. Three of these TMs were directly referenced as being used for the treatment of DM: Moringa (Moringa oleifera), lemongrass (Cymbopogon citrullus), and African redwood (Hagenia abyssinica) (Table 3 \& Additional File 2). We further identified five plant-based TMs relevant in the treatment and management of DM. These were referenced as being in use by the local population for other conditions (Table 4 \& Additional File 2): Aloe (Aloe vera), Horsewood (Clausena anisata), Pigeon pea (Cajanus cajan), African wormwood (Artimisia afra), and Avocado (Persea americana). All of the TMs were identified as relevant for DM care had a wide-range of effects that could be potentially beneficial or harmful.

\section{Discussion}

The prevalence of TM use was high among individuals with DM and those at increased risk for DM in Northern Tanzania, and the plant-based TMs commonly used towards DM care had numerous effects. Individuals with and at risk for DM sought healthcare advice from many non-biomedical practitioners including family members, community and tribal elders, friends, traditional healers, and herbal vendors. In addition, TMs were a common treatment choice for DM, and many individuals with DM used TM and biomedicine concurrently.

TMs are now recognized globally as important components of healthcare systems [9-11, 13]. In sub-Saharan 


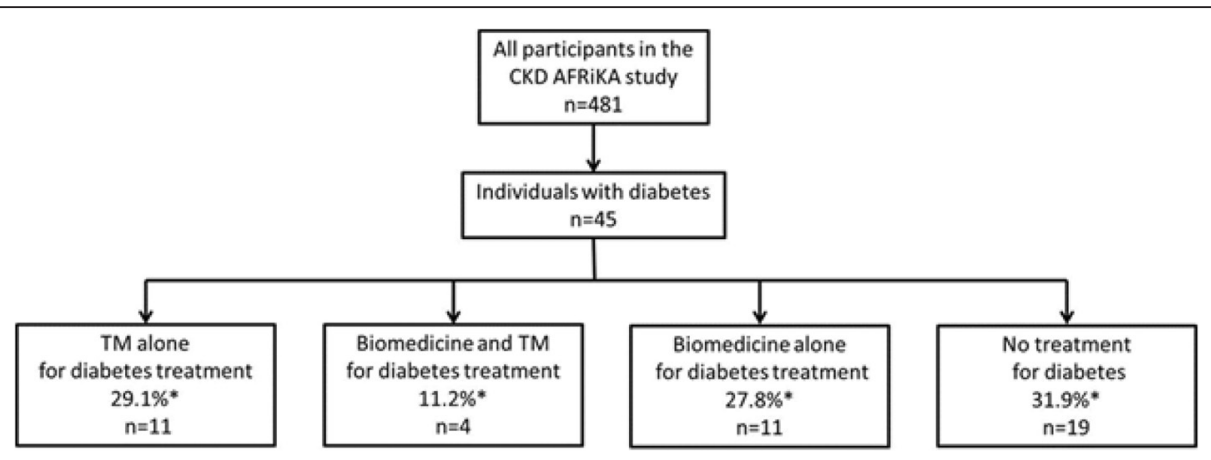

Fig. 1 Treatment choices for diabetes care among individuals with diabetes in Northern Tanzania; CKD AFRiKA, 2014. *Prevalence rates were sample-balanced using age- and gender-weights based on the 2012 district-level census data

Africa, TMs remain critical in meeting the healthcare needs for many individuals. However, with the rising burden of NCDs across sub-Saharan Africa [3, 4], the continued role and importance of TMs in NCD management is less clear. As such, our study, which highlights TM practices among individuals with diabetes in northern Tanzania, fills an important gap. In resource-limited health facilities across Tanzania and sub-Saharan Africa, taking a patient- or community-centered approach that is sensitive to treatment preferences may be most effective, especially for improving NCD management. For example, understanding high and low risk plant-based TMs may be one approach to incorporate TM preferences into an NCD management program [22-24]. Additionally, educating TM practitioners and other key stakeholders about safe and appropriate NCD care, including timely referrals to biomedical practitioners, may also be an effective approach to incorporate TM preferences into NCD management programs. Other potential strategies could include training community health workers to deliver locally-relevant medical care to patients with DM, developing community-based outreach programs that include DM education consistent with local health belief systems and practices, or incorporating family members and caregivers into health interventions $[4,14]$.

In order to develop such programs and policies, we need to facilitate healthcare decisions that can leverage the benefits of TMs while mitigating the risks. As such, a better understanding of the clinical safety, efficacy, and quality of TMs in local settings is urgently needed. Moreover, governments should establish a framework for accreditation, registration, and regulation of TM practitioners [22, 23]. Among the TMs that we identified, they all had numerous pharmacologically active compounds and a variety of effects. Potential beneficial effects for individuals with DM included blood pressure lowering, anti-microbial, antiinflammatory, anti-oxidative, and lipid lowering properties. Additionaly, several of them, including Cymbopogon cirtullus [25, 26], Moringa oleifera [27], Aloe vera [28], Clausean anista [29], Cajanus cajan [30, 31], Persea americana [32] and Artimisia afra [33], also had direct glucose-lowering effects, with some having specific effects on glucose metabolism.

On the other hand, all the TMs we identified also had potentially harmful side effects, including nephrotoxicy, optic atrophy, hepatotoxicity, and volume depletion among others, which may be particularly relevant for individuals with DM who often suffer several comorbidities. Our findings extend the work of others across the region by stressing the importance of equipping both biomedical providers and traditional healers with resources and education that can facilitate evidence-based discussions regarding TM use among their patient populations. For example, Clausena anisata (Horsewood) has numerous potential benefits for individuals with $\mathrm{DM}$, including blood pressure lowering through inhibition of angiotensin-converting enzyme, which may be particularly important among those with proteinuria [34]. However, it also exhibits a dosedependent inhibition of many reverse transcriptase inhibitors commonly used in the treatment of HIV [35]. Also, Aloe vera is commonly and effectively used topically to treat burns and minor skin conditions, but when boiled and ingested in large amounts to treat dyspepsia, it can cause acute kidney and liver injuries. Therefore, through understanding these important effects and practices, providers caring for individuals with DM may be able to tailor interventions in ways that are effective yet also patient-centered and sensitive to healthcare-seeking preferences.

We noted a few limitations in our study. Our crosssectional design does not allow causal pathways to be established and associations may be confounded by unmeasured variables. Additionally, non-response bias may be present, and to reduce this potential bias we used sample-balanced weights when reporting prevalence estimates. Also, around culturally sensitive topics such as 
Table 3 Plant-based traditional medicines used for treatment of diabetes in the Kilimanjaro Region, Tanzania

\begin{tabular}{|c|c|c|c|c|c|c|}
\hline Nomenclature & & & Uses in other African communities & Active Compounds and Pharmacology & Plant Parts in Use & Potential Side Effects \\
\hline Scientific & $\begin{array}{l}\text { English Common } \\
\text { Name(s) }\end{array}$ & $\begin{array}{l}\text { Local } \\
\text { Vernacular }\end{array}$ & & & & \\
\hline $\begin{array}{l}\text { Moringa } \\
\text { oleifera }^{a}\end{array}$ & $\begin{array}{l}\text { Moringa; } \\
\text { Drumstick tree }\end{array}$ & Mlonge & $\begin{array}{l}\text { Senegal: stimulates breastmilk production, } \\
\text { diabetes, anxiety, diarrhea and dysentery, } \\
\text { colitis, gonorrhea, and various skin infections } \\
\text { Chad: nutritional supplementation } \\
\text { Nigeria and Benin: toothaches, Gl ailments } \\
\text { (dyspepsia, ulcers, and aiding digestion), poor } \\
\text { vision, joint pains, diabetes, anemia, hypertension, } \\
\text { paralysis, and helminthic infestation } \\
\text { Uganda: diabetes, hypertension, HIV/AIDS-related } \\
\text { symptoms, stimulates breastmilk production }\end{array}$ & $\begin{array}{l}\text { Leaf extracts have glucose metabolism } \\
\text { effects: modulates gene-expression of } \\
\text { gluconeogenic liver enzymes, and } \\
\text { regenerates pancreatic beta cells } \\
\text { Nitrile and mustard oil glycosides: } \\
\text { lowers blood pressure } \\
\text { Seed kernels: bronchodilatory properties } \\
\text { CNS effects: increases glutamate and } \\
\text { serotonin; decreases norepinephrine } \\
\text { and dopamine; anti-pyretic } \\
\text { properties } \\
\text { Anti-oxidative properties: may prevent } \\
\text { drug-induced nephrotoxicity, myocardial } \\
\text { damage, and gastric mucosal irritation } \\
\text { Active compounds: salicylic and ferulic acids, } \\
\text { flavonoids, phenolic acids, glucosinolates } \\
\text { and isothiocanates, tannins and saponins }\end{array}$ & $\begin{array}{l}\text { Flowers Pods/seeds } \\
\text { Roots Leaves (Commonly } \\
\text { grounded into powder } \\
\text { for mixing) }\end{array}$ & $\begin{array}{l}\text {-Abortifacient: } \\
\text { causes uterine } \\
\text { contractions } \\
\text {-Inhibits CYP3A4 } \\
\text { (inhibits metabolism } \\
\text { of anti-diabetic drugs } \\
\text { in the meglitinide class) } \\
\text {-Chronic kidney disease } \\
\text { (decline in glomerular } \\
\text { filtration rate) } \\
\text {-Hepatotoxicty (potentia } \\
\text { at high doses) } \\
\text {-Paralysis }\end{array}$ \\
\hline $\begin{array}{l}\text { Cymbopogon } \\
\text { Citrullus }^{\mathrm{a}}\end{array}$ & Lemongrass & Mchaichai & $\begin{array}{l}\text { Southern Africa: diabetes, oral thrush, } \\
\text { anti-tussive, anti-emetic, antiseptic, arthritis } \\
\text { West Africa (Cameroon \& Nigeria): } \\
\text { antipyretic/anti-malarial, stimulant, } \\
\text { anti-spasmodic, jaundice } \\
\text { Mauritius: common cold, pneumonia, fever, } \\
\text { Gl ailments and dyspepsia }\end{array}$ & $\begin{array}{l}\text { Oil extracts: anti-bacterial, anti-amebic, anti-fungal, } \\
\text { antimalarial, anti-protozoal, and antifilarial effects } \\
\text { Phenol and flavonoids: antioxidative } \\
\text { Citral: insect repellent } \\
\text { Active compounds: terpenes, alcohols, ketons, } \\
\text { aldehyde, flavanoids, phenols, citral }\end{array}$ & $\begin{array}{l}\text { Leaves } \\
\text { Stem } \\
\text { Oil } \\
\text { extract }\end{array}$ & $\begin{array}{l}\text {-Volume depletion } \\
\text {-Diarrhea } \\
\text {-Somnolence } \\
\text {-Chronic kidney disease } \\
\text { (decline in glomerular } \\
\text { filtration rate) } \\
\text {-Gastritis } \\
\text { - Hepatotoxicty } \\
\text { (potential) } \\
\text {-Hypoglycemia }\end{array}$ \\
\hline $\begin{array}{l}\text { Hagenia } \\
\text { abyssinica }^{a}\end{array}$ & $\begin{array}{l}\text { African redwood; East } \\
\text { African rosewood }\end{array}$ & $\begin{array}{l}\text { Enjani engashe } \\
\text { (Maasai) }\end{array}$ & $\begin{array}{l}\text { Ethiopia: Helminthic infections, Typhoid fever, } \\
\text { wound healing, epilepsy, sexually transmitted } \\
\text { diseases, and symptomatic ailments (dyspepsia, } \\
\text { diarrhea, common cold, and cough) }\end{array}$ & $\begin{array}{l}\text { Essential oils: trypanocidal (anti-spasmodic) and } \\
\text { cytotoxic (in vitro activity against leukemic and } \\
\text { adenocarcinoma cell lines) } \\
\text { Active compounds: kosin (a phloroglucinol), } \\
\text { \& quercetin glucuronides }\end{array}$ & Flower and leaf extracts & $\begin{array}{l}\text {-Hepatotoxicity } \\
\text {-Diarrhea and volume } \\
\text { depletion } \\
\text { - Gastritis } \\
\text {-Optic atrophy } \\
\text { (blindness) } \\
\text {-Abortifacient }\end{array}$ \\
\hline
\end{tabular}

CNS central nervous system, CYP3A4 Cytochrome P450 3A4, Gl gastrointestinal

a References are available in Additional file 2 
Table 4 Plant-based traditional medicines relevant for the treatment and management of diabetes in Kilimanjaro Region, Tanzania Nomenclature Uses in other African communities Active Compounds and Pharmacology

\begin{tabular}{lll}
\hline Scientific & $\begin{array}{l}\text { Common } \\
\text { Name(s) }\end{array}$ & Local \\
& Vernacular \\
\hline
\end{tabular}

Aloe vera Cape aloes, Aloe, Alovera

(ferox and Aloe Vera

secundiflora

species) $)^{\mathrm{a}}$

Clausena Horsewood Mjafari anisata $^{a}$

Africa: arthritis, burns/skin

conditions, hypertension, purging/laxative

dyspepsia, anti-inflammatory, cosmetics, eye

ailments/conjunctivitis, sexually transmitted

diseases, infertility, impotence

East Africa (Kenya, Uganda, Ethiopia, and

Tanzania): malaria, purging/laxative for

cleansing purposes, dyspepsia, skin

ulcerations/wound healing including

burns, HIV/AIDS, cosmetic, infertility,

anti-parasitic

West Africa: bacterial and fungal infections

of the skin including boils, ringworm, and eczem

East Africa (Tanzania): oral candidiasis, fungal infections of the skin, and epilepsy Southern Africa: epilepsy, arthritis, rheumatism and other inflammatory conditions, hypertension,

heart failure and other heart ailments, schistosomiasis, taeniasis and other parasitic infections, constipation and dyspepsia; malaria and other febrile conditions, headaches, eye ailments/conjunctivitis, impotence and infertility

Ghana: diabetes, dysentery, hepatitis, measles, dysmenorrhea

Nigeria: wound healing, aphthae, bedsores, and malaria/fever

West Africa (Nigeria, Togo, Ivory Coast):
Gel: Prostaglandin- and bradykinase-mediated

anti-inflammatory activity.

Aloin leaf extracts: increases GI motility

and induces emesis

Active compounds: glucomannans,

thiamine, niacin, riboflavin, bradykinase

anthraquinone glycosides (aloin, barbaloin)

$\begin{array}{ll}\text { Gel } & \text {-Volume depletion and } \\ \text { extract } & \text { electrolyte imbalance } \\ \text { Leaves } & \text {-Hypoglycemia } \\ \text { Rind } & \text { Hyperpigmentation and } \\ \text { Stem } & \text { photosensitivity } \\ & \text {-Hepatotoxicity } \\ & \text {-Acute tubular necrosis } \\ & \text {-Acute interstitial nephritis }\end{array}$

Leaf extracts inhibit ACE: may lower blood pressure

Bacteriostatic against gram positive and

gram negative bacteria; Fungicidal activity

against Aspergilus fumigatus

Antiplasmodial: in-vitro dose-dependent

schizonticidal effect of leaf extracts on

parasitemia

In vitro activity against leukemic cell lines

Anti-HIV1/2 effects: dose-dependent inhibition

of reverse transcriptase and taq polymerase enzymes

Hypoglycemic properties (reduction in basal blood

glucose levels); Anti-convulsant; ACE inhibition;

Cyclooxygenase-1 and -2 (weak) inhibition

Active compounds:

Clausamine, carbazole alkaloids (girinimbine,

murrayamine-A, and ekeberginine), flavonoids,

monoterpenes, and coumarins

Antibacterial activity; hypocholesterolemic effects

(diet-induced): inhibits CNS voltage-gated Na channels; Seeds

induces apoptosis in human breast cancer cells via a

ROS-mediated mitochondrial pathway; inhibits TNF-a and IL-1 $\beta$ production

Glycemic profile: leaves induce hyperglycemia,

seeds induce hypoglycemia

Active compounds.

Cajanuslactone, stilbene, pinostrobin, cajano

Anti-inflammatory, limiting lowering ( $\beta$-Carotene and fatty acids), anticonvulsive (via gabanergic effects) \& vasodilatory properties; Inhibits

alpha-amylase and enhance glycogenesis;

acetogenins inhibit platelet

aggregation; larvicidal to Aedes aegypti

Active Compounds:
Leaf, -Heavy metal bio-accumulation stem, and (Iron, cadmium, manganese) root -Hypoglycemia extracts -Gastritis

-CNS depression

-Somnolence

-Heavy metal bio-accumulation (arsenic, copper, aluminum)

-Bronchospasm

-Hypoglycemia
Leaves

Fruits

Seed

Rind

Bark combined with other anti-coag ulants

-Hyperkalemia (especially among those with impaired kidney 
Table 4 Plant-based traditional medicines relevant for the treatment and management of diabetes in Kilimanjaro Region, Tanzania (Continued)

\begin{tabular}{|c|c|c|c|c|c|c|}
\hline $\begin{array}{l}\text { Artemisia } \\
\text { afra }^{a}\end{array}$ & $\begin{array}{l}\text { African } \\
\text { wormwood }\end{array}$ & $\begin{array}{l}\text { Fivi, Majani } \\
\text { mapana } \\
\text { artemisia }\end{array}$ & $\begin{array}{l}\text { Southern Africa: coughs, colds, sore throat, } \\
\text { gastritis/reflux, hemorrhoids, fevers, malaria, } \\
\text { asthma, diabetes }\end{array}$ & $\begin{array}{l}\text { Lowers blood glucose, improves glucose } \\
\text { tolerance and balance in lipid metabolism; } \\
\text { anti-oxidative properties } \\
\text { bactericidal against gram positive and gram } \\
\text { negative bacteria }\end{array}$ & $\begin{array}{l}\text { Roots } \\
\text { stems } \\
\text { leaves }\end{array}$ & $\begin{array}{l}\text { - Chronic kidney } \\
\text { disease (decline in } \\
\text { glomerular filtration } \\
\text { rate) } \\
\text {-Acute tubular necrosis } \\
\text {-Hypoglycemia }\end{array}$ \\
\hline
\end{tabular}

Gl gastro-intestinal, ACE angiotensin converting enzyme, TNF tumor necrosis factor, IL interleukin, CNS central nervous system, ROS reactive oxygen species

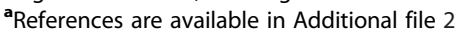


TMs, reporting and recall bias are a concern. To reduce these biases, we used only local native surveyors who spoke Swahili as their first language, conducted the interviews in private when possible, and pre-tested the survey instruments for content validity and design flaws. Misclassification of disease may also be present, and though we expect most misclassification to be non-differential, the measurement we used to diagnose diabetes (HbA1c) has not been validated in this population. As such, the sensitivity and specificity of the test at a cutoff value of $7.0 \%(53 \mathrm{mmol} / \mathrm{mol})$ are not known for this population.

\section{Conclusion}

In conclusion, the prevalence of TM use was high among individuals with DM as well as those at increased risk for DM in northern Tanzania, and many of these individuals use TMs and biomedicines together. Individuals with DM sought healthcare advice from several sources, and biomedical providers need to be aware of these practices, especially as they pertain to TM use. The TMs commonly used by individuals with DM in northern Tanzania have a wide range of effects, and understanding these effects will help shape biomedical practitices and public health policies that are effective yet also patient-centered and sensitive to local TM preferences.

\section{Additional files}

Additional file 1: Structured Survey Instrument for the use of Traditional Medicines (English and Swahili). (DOCX $454 \mathrm{~kb}$ )

Additional file 2: Supplementary references for Traditional Medicines used for the treatment of diabetes in Northern Tanzania. (DOCX 28 kb)

\section{Abbreviations}

$\mathrm{Cl}$, confidence intervals; CKD AFRiKA, Comprehensive Kidney Disease Assessment for Risk Factors, epidemiology, Knowledge, and Attitudes; COPD, chronic obstructive pulmonary disease; DM, diabetes mellitus; FGD, focus group discussion; HbA1c, Hemoglobin (Hb) A1c; HIV, human immunodeficiency virus; KCMC, Kilimanjaro Christian Medical College; NCD, non-communicable disease; TM, traditional medicine

\section{Acknowledgments}

We would like to thank Professors G. Ralph Corey and John Bartlett, and all the staff of the KCMC-Duke Collaboration in Moshi, Tanzania for all of their efforts. We give a special thanks to Carol Sangawe, Cynthia Asiyo, and Nicola West for their integral role implementing the study and Jeffrey Hawley and Audrey Brown at the Duke Office of Clinical Research for their help in data management. We are also grateful to Estomih Mduma and his team for their help with Swahili translation needs as well as Professor Doris Payne of the University of Oregon Department of Linguistics who assisted us with Maasai translations.

\section{Funding}

This study was supported by an NIH Research Training Grant (\#R25 TW009337) funded by the Fogarty International Center and the National Institute of Mental Health; a Research and Prevention Grant funded by the International Society of Nephrology Global Outreach Committee; and a Master's of Science research stipend from the Duke Global Health Institute. There was no involvement by the funding source in the design, analysis, or writing of this study. All authors had full access to the data and had final responsibility for the decision to publish.

\section{Availability of data and materials}

The dataset supporting the conclusions of this article is available on the Duke University secure data server managed by the Duke Office of Clinical Research. The data can be provided upon requests sent to the corresponding author.

\section{Authors' contributions}

$J \mathrm{~L}$ contributed to the data analysis and manuscript preparation. DW contributed to the data analysis and manuscript preparation. VM contributed to the study design, data collection, and manuscript preparation. FK contributed to the data collection, data analysis, and manuscript preparation. DB contributed to the data analysis and manuscript preparation. JO contributed to the data analysis and manuscript preparation. UPD contributed to the study design, data analysis, and manuscript preparation. JWS contributed to the study design, data collection, data analysis, and manuscript preparation. All authors read and approved the final manuscript.

\section{Competing interests}

The authors declare that they have no competing interests.

\section{Consent for publication}

Not applicable.

\section{Ethics approval and consent to participate}

The study protocol was approved by Duke University Institutional Review Board (\#Pro00040784), the Kilimanjaro Christian Medical College (KCMC) Ethics Committee (EC\#502), and the National Institute for Medical Research in Tanzania. The consent forms were administered verbally to all participants, and written informed consent (by signature or thumbprint) was obtained from all participants.

\section{Author details}

'Duke Global Health Institute, Duke University, 310 Trent Drive, Durham, NC 27705, USA. ${ }^{2}$ Kilimanjaro Christian Medical University College, Moshi, Tanzania. ${ }^{3}$ National Institute for Medical Research, Dar es Salaam, Tanzania. ${ }^{4}$ Departments of Medicine and Pediatrics, Duke Clinical Research Institute, Durham, NC, USA. ${ }^{5}$ Division of Nephrology, Department of Medicine, Duke University School of Medicine, Durham, NC, USA. ${ }^{6}$ Duke Clinical Research Institute, Duke University, Durham, NC, USA.

Received: 3 August 2016 Accepted: 5 August 2016

Published online: 11 August 2016

\section{References}

1. IDF Diabetes Atlas, 7th ed. http://www.diabetesatlas.org/\#. Accessed 8 Aug 2016

2. Renzaho AM. The post-2015 development agenda for diabetes in sub-Saharan Africa: challenges and future directions. Glob Health Action. 2015;8:27600.

3. Naghavi M, Forouzanfar MH. Burden of non-communicable diseases in sub-Saharan Africa in 1990 and 2010: Global Burden of Diseases, Injuries, and Risk Factors Study 2010. Lancet. 2013;381:S95.

4. Hall V, Thomsen RW, Henriksen O, Lohse N. Diabetes in Sub Saharan Africa 1999-2011: Epidemiology and public health implications. A systematic review. BMC Public Health. 2011;11:564.

5. Peck R, Mghamba J, Vanobberghen F, et al. Preparedness of Tanzanian health facilities for outpatient primary care of hypertension and diabetes: a cross-sectional survey. Lancet Global Health. 2014;2(5):e285-92.

6. Katende D, Mutungi G, Baisley K, et al. Readiness of Ugandan health services for the management of outpatients with chronic diseases. Trop Med Int Health. 2015;20(10):1385-95.

7. World Health Organization. WHO Traditional Medicine Strategy 2002-2005. Geneva: WHO; 2002. WHO/EDM/TRM/2002.1.

8. Brown JB, Ramaiya K, Besançon S, et al. Use of medical services and medicines attributable to diabetes in sub-Saharan Africa. PLoS One. 2014; 9(9):e106716.

9. OAU. The Lusaka Declaration of the African Summit of Heads of State and Government on designation of the period 2001-2010 as the OAU Decade for African traditional medicine. Addis Ababa: OAU; 2001.

10. WHO. Review of the End-of-Decade on African traditional medicine (2001-2010) (prepared for the Conference of African Ministers of Health, Windhoek, Namibia, 17-21 April 2011). Brazzaville: WHO Regional Office for Africa; 2011 
11. WHO. Enhancing the role of traditional medicine in health systems: A Strategy for the African Region (2013-2023), (Document AFR/RC63/6) and Resolution (AFR/RC63/R3). Sixty-third Session of WHO Regional Committee for Africa, 2-6 September 2013. Brazzaville, Republic of Congo. 2013.

12. Stanifer JW, Lunyera J, Boyd D, Karia F, Maro V, Omolo J, Patel UD. Traditional medicines used for chronic kidney disease: an ethnomedical survey. BMC Nephrol. 2015;16(1):170.

13. WHO Congress on Traditional Medicine, Beijing, China, November 2008. http:// www.who.int/medicines/areas/traditional/congress/beijing_declaration/en/. Accessed 8 Aug 2016.

14. Stanifer JW, Patel UD, Karia F, et al. The determinants of traditional medicine use in Northern Tanzania: a mixed methods study. PLoS One. 2015;10(4):e0122638.

15. Metta E, Bailey A, Kessy F, Geubbels E, Hutter I, Haisma H. "In a situation of rescuing life": meanings given to diabetes symptoms and care-seeking practices among adults in Southeastern Tanzania: a qualitative inquiry. BMC Public Health. 2015;15:224.

16. Moshi MJ, Otieno DF, Weisheit A. Ethnomedicine of the Kagera Region, Northwestern Tanzania. Part 3: plants used in traditional medicine in Kikuku village, Muleba District. J Ethnobiol Ethnomed. 2012;8:14.

17. Sawe HR, et al. Disease patterns and clinical outcomes of patients admitted in intensive care units of tertiary referral hospitals of Tanzania. BMC Int Health Hum Rights. 2014;14:26.

18. United Republic of Tanzania. 2012 Population and Housing Census. Dar es Salaam: Central Census Office and National Bureau of Statistics; 2013.

19. Stanifer JW, Karia F, Voils Cl, et al. Development and validation of a cross-cultural knowledge, attitudes, and practices survey instrument for chronic kidney disease in a Swahili-speaking population. PLoS One. 2015;10(3):e0121722.

20. Stanifer JW, Maro V, Egger J, Karia F, Thielman N, Turner EL, et al. The Epidemiology of Chronic Kidney Disease in Northern Tanzania: a population-based survey. PLoS One. 2015;10(4):e0124506.

21. Harris PA, Taylor R, Thielke R, Payne J, Gonzalez N, Conde JG. Research electronic data capture (REDCap) - A metadata-driven methodology and workflow process for providing translational research informatics support. J BioMed Inform. 2009;42(2):377-81.

22. Kasilo OM, Trapsida JM. Regulation of Traditional Medicine in the WHO African Region. The African Health Monitor [special issue], 31 August 2010; WHO Regional Office for Africa. http://ahm.afro.who.int/special-issue14/ahmspecial-issue-14.pdf. Accessed 8 Aug 2016.

23. WHO. Guidelines for Clinical Study of Traditional Medicines in the WHO African Region. Regional Office for Africa, Republic of Congo. 2004. http://apps.who. int/medicinedocs/documents/s21350en/s21350en.pdf. Accessed 8 Aug 2016.

24. Ben-Arye E, Samuels N, Goldstein LH, et al. Potential risks associated with traditional herbal medicine use in cancer care: a study of middle eastern oncology health care professionals. Cancer. 2016;122(4):598-610.

25. Boaduo NK, Katerere D, Eloff JN, Naidoo V. Evaluation of six plant species used traditionally in the treatment and control of diabetes mellitus in South Africa using in vitro methods. Pharm Biol. 2014;52(6):756-61.

26. Adeneye AA, Agbaje EO. Hypoglycemic and hypolipidemic effects of fresh leaf aqueous extract of Cymbopogon citratus Stapf. in rats. J Ethnopharmacol. 2007;112(3):440-4

27. Abd El Latif A, El Bialy Bel S, Mahboub HD, Abd Eldaim MA. Moringa oleifera leaf extract ameliorates alloxan-induced diabetes in rats by regeneration of $\beta$ cells and reduction of pyruvate carboxylase expression. Biochem Cell Biol. 2014;92(5):413-9.

28. Vogler BK, Ernst E. Aloe vera: a systematic review of its clinical effectiveness. Br J Gen Pract. 1999;49(447):823-8.

29. Ojewole JA. Hypoglycaemic effect of Clausena anisata (Willd) Hook methanolic root extract in rats. J Ethnopharmacol. 2002;81:231-7.

30. Jaiswal D, Rai PK, Kumar A, Watal G. Study of glycemic profile of Cajanus cajan leaves in experimental rats. Indian J Clin Biochem. 2008;23:167-70.

31. Ezike AC, Akah PA, Okoli CC, Okpala CB. Experimental evidence for the antidiabetic activity of cajanus cajan leaves in rats. J Basic Clin Pharm. 2010;1:81-4.

32. Karou SD, Tchacondo T, Djikpo Tchibozo MA, Abdoul-Rahaman S, Anani K, Koudouvo K, et al. Ethnobotanical study of medicinal plants used in the management of diabetes mellitus and hypertension in the Central Region of Togo. Pharm Biol. 2011;49(12):1286-97.

33. Sunmonu TO, Afolayan AJ. Protective effect of Artemisia afra Jacq. on isoproterenol-induced myocardial injury in Wistar rats. Food Chem Toxicol. 2010;48:1969-72.
34. Duncan AC, Jäger AK, van Staden J. Screening of Zulu medicinal plants for angiotensin converting enzyme (ACE) inhibitors. J Ethnopharmacol. 1999; 68(1-3):63-70.

35. Ayisi NK, Nyadedzor C. Comparative in vitro effects of AZT and extracts of Ocimum gratissimum, Ficus polita, Clausena anisata, Alchornea cordifolia, and Elaeophorbia drupifera against HIV-1 and HIV-2 infections. Antiviral Res. 2003;58(1):25-33.

\section{Submit your next manuscript to BioMed Central and we will help you at every step:}

- We accept pre-submission inquiries

- Our selector tool helps you to find the most relevant journal

- We provide round the clock customer support

- Convenient online submission

- Thorough peer review

- Inclusion in PubMed and all major indexing services

- Maximum visibility for your research

Submit your manuscript at www.biomedcentral.com/submit
Biomed Central 